\title{
The Role of Vitamin D in Cancer Prevention
}

\author{
Does UV Protection Conflict With the Need to Raise Low Levels of Vitamin D?
}

Hajo Zeeb, Rüdiger Greinert

\section{SUMMARY}

Background: Vitamin D is essential for life. Part of the body's supply of vitamin D is ingested in food, but UV induced vitamin D synthesis in the body plays an even more important role. UV irradiation is a cause for the currently rising incidence of skin cancer in many countries; on the other hand, Vitamin D might be protective against some cancers. In this paper we summarize the current data on vitamin $D$ and cancer and on the vitamin D status of populations in Europe and discuss whether current recommendations on UV protection require changes.

Methods: In 2008, the International Agency for Research on Cancer (IARC) published a systematic review on vitamin $D$ and cancer. We describe its main findings and review additional publications retrieved by a selective literature search on vitamin D, UV light, and skin cancer. In addition, we systematically review the current recommendations on vitamin D supplementation.

Results: Higher vitamin D levels are associated with a lower risk of colon cancer. For breast cancer, the situation is less clear. In general, higher vitamin D levels are associated with lower overall mortality. Concerning optimal Vitamin D levels, serum values $\geq 50 \mathrm{nmol} / \mathrm{L}$ (ie.. $\geq 20 \mathrm{ng} / \mathrm{mL}$ ) are frequently discussed, and a few authors favor markedly higher values. Brief UV exposures are usually adequate for endogenous vitamin $D$ synthesis.

Conclusion: More research is needed into the possible protective effects of vitamin D against cancer. Brief, daily UV exposure stimulates vitamin D production and causes negligible skin damage. Raising the vitamin D level even further by extended solar UV exposure or irradiation in a Institut für Medizinische Biometrie, Epidemiologie und Informatik (IMBEI), Universitätsmedizin der Johannes GutenbergUniversität Mainz; Bremer Institut für Präventionsforschung und Sozialmedizin Universität Bremen: Prof. Dr. med. Zeeb Molekulare Zellbiologie, Dermatologisches Zentrum, Elbe Kliniken, solarium is inadvisable because of the risk of skin cancer. Oral vitamin D supplementation can be considered as an alternative, particularly for persons at high risk, such as the elderly and members of certain ethnic groups.

Gite this as: Dtsch Arztebl Int 2010; 107(37): 638-43 DOl: 10.3238/arztebl.2010.0638
V itamin D is a necessary substance for life whose synthesis in the skin is induced by ultraviolet radiation. It is also contained in various types of food, including fish and eggs. Generally, however, the dietary intake of vitamin D has no more than a moderate influence on the vitamin D level, which is measured as the serum concentration of 25-hydroxyvitamin D $(1,2)$ (eBox 1).

Vitamin D is known to have beneficial effects on bone formation and on the neuromuscular system. In recent years, scientific attention has been devoted to its potential preventive effects against chronic diseases of various types, particularly cancer. Currently, there are active research efforts, as well as scientific debate, about a number of mechanisms, including antiproliferative effects and potential influences on cell differentiation and angiogenesis (3). Observational epidemiological studies are providing more plentiful evidence that high levels of vitamin D might protect against certain types of cancer, such as cancer of the bowel (4) and breast (5). Yet the reality of such preventive effects remains an open question, nor is there any scientific consensus about the optimal serum vitamin D concentration at which they are supposed to take place. Further controversy surrounds the issue of how adequate vitamin $\mathrm{D}$ levels should be achieved in the population at large.

Sunlight is the main source of UV light for vitamin $\mathrm{D}$ photosynthesis in man, but it is also the main risk factor for both melanocytic and non-melanocytic skin cancer (6). On the basis of statistics from the Schleswig-Holstein Cancer Registry for the year 2002 (7), it is estimated that, in Germany alone, some 140000 people develop basal cell carcinoma, squamous cell carcinoma, and malignant melanoma each year. The high and, in some cases, rising incidence of these types of cancer is considered a public health problem in many countries where light-skinned persons make up a large percentage of the population. Therefore, many groups have issued recommendations, including the World Health Organization (WHO), the International Commission on Non-Ionizing Radiation Protection (ICNIRP), and the European Society of Skin Cancer Prevention (EUROSKIN), and many prevention campaigns have been initiated, such as those of the 
German Task Force on Dermatological Prevention (Arbeitsgemeinschaft Dermatologische Prävention, ADP) and the German Cancer Aid Society (Deutsche Krebshilfe, DKH). The recommendations specify that UV protection should not be performed in such a way as to endanger the formation of adequate amounts of vitamin $\mathrm{D}$, but they also advise against excessive UV exposure in the pursuit of higher vitamin D levels. This advice concerns exposure to the sun as well as artificial UV radiation in solaria.

This article provides an overview of the epidemiological data on vitamin $\mathrm{D}$ and a discussion of the available studies on the link between vitamin D and cancer, along with the recommendations for daily vitamin D intake in various countries around the world. In view of the known carcinogenic effect of UV radiation on the skin, alternative means of achieving an adequate vitamin D level are critically discussed.

\section{Methods}

The International Agency for Research on Cancer (IARC) recently published an extensive documentation and systematic review of the link between vitamin D and cancer (6). In this paper, we present the main conclusions of the IARC report and supplement them with the findings of a selective review of relevant literature from the years 2000 to 2009. We retrieved this literature by searching the PubMed database for publications on the etiology and prevention of chronic diseases with vitamin $\mathrm{D}$, serum vitamin $\mathrm{D}$ levels in the general population, and on ultraviolet light and cancer; the search terms were "vitamin D," “cholecalciferol," "ultraviolet light,” "sunlight,” “cancer,” "skin cancer,” and "prevention."

For the international recommendations on vitamin D intake, we systematically searched the websites of the international medical societies and made use of crossreferences from the other publications that were available to us.

\section{Results}

\section{Vitamin D levels in the general population}

Population-based data on vitamin D status are available from a large number of epidemiological studies that have been performed in many countries. In Europe, evidence of vitamin D deficiency has not just been found in previously known risk groups, such as the elderly (8), persons from an immigrant background, persons with dark skin, and persons who cover most or all of their skin for religious or cultural reasons (9) Note: I have added "or cultural" because it is debatable whether the near-complete veiling of some Muslim women is actually a religious requirement; middleaged persons in the general population also commonly have vitamin D deficiency, which is defined as a concentration of 25(OH)vitamin $\mathrm{D}$ that is below 50 $\mathrm{nmol} / \mathrm{L}$, or marked vitamin D deficiency (a concentration below $25 \mathrm{nmol} / \mathrm{L}$ ) (10). Persons who frequently expose themselves to sunlight in the summer can achieve values in the vicinity of $120 \mathrm{nmol} / \mathrm{L}$, with

\section{TABLE 1}

Exposure times needed to achieve vitamin D concentrations of 200,400 , and $600 \mathrm{IU}$, depending on the UV index

\begin{tabular}{l|l|l|l|l|l|l}
\hline \multicolumn{5}{|c|}{ UV index (1 = low, 12 = high) } \\
\begin{tabular}{|l|l|l|l|l}
\hline \\
Exposure time (min) for the production of:
\end{tabular} & 1 & 3 & 6 & 12 \\
\hline 200 IU vitamin D & 46 & 15 & 8 & 4 \\
\hline 400 IU vitamin D & 93 & 31 & 16 & 8 \\
\hline 600 IU vitamin D & 140 & 47 & 24 & 12 \\
\hline $\begin{array}{l}\text { Skin type II: minimal erythema doses per hour } \\
\text { (MED/h) }\end{array}$ & 0.42 & 1.26 & 2.52 & 5.04 \\
\hline
\end{tabular}

For a person with skin type II, the exposure of $6 \%$ of the skin surface to one minimal erythema dose $\left(M E D=210 \mathrm{~J} / \mathrm{m}^{2}\right)$ results in the production of $600 \mathrm{IU}$ of vitamin $\mathrm{D}(\mathrm{e} 19)$. One unit on the UV index corresponds to an irradiation intensity of $0.42 \mathrm{MED} / \mathrm{h}$. These figures were used to generate the table above. The minimal erythema doses for less UV-sensitive skin types (types III and IV) range from 350 to $450 \mathrm{~J} / \mathrm{m}^{2}$.

The exposure times for skin types III and IV would be easy to calculate from this information and from the measured figure of $600 \mathrm{IU}$ Vit D per $210 \mathrm{~J} / \mathrm{m}^{2}$ for skin type II if there were a simple, linear relationship between the exposure time and vitamin D production. Recent studies have revealed, however, that vitamin D production involves as many as 9 different (photo-)isomerization reactions; thus, simple, linear extrapolation of data from skin type II to other skin types would be a misleading oversimplification. It remains true, of course, that the exposure times for skin types III and IV are longer than those for skin type II that are listed in the table.

markedly lower levels in winter (11). Different studies of vitamin D status are often difficult to compare with one another because of the lack of standardized measuring techniques, in addition to varying definitions of normal and low serum levels.

The German Federal Health Survey (Bundesgesundheitssurvey) for 1998 revealed vitamin D concentrations below $50 \mathrm{nmol} / \mathrm{L}$ in over half of all participants ( $58 \%$ of men and $57 \%$ of women), as well as a marked seasonal fluctuation, with much lower levels in winter (12). Among premenopausal women serving as normal controls in a case-control study on breast cancer in the Rhine-Neckar area, 16\% had vitamin D levels below 30 $\mathrm{nmol} / \mathrm{L}$, while only $21.5 \%$ had levels of $75 \mathrm{nmol} / \mathrm{L}$ or higher (13).

According to the German Health Interview and Examination Survey for Children and Adolescents (Kinder- und Jugendgesundheitssurvey) of the Robert Koch Institute (Germany's equivalent of the Centers for Disease Control and Prevention), 30\% of children aged 3 to 17 with an immigrant background have a vitamin D level below $25 \mathrm{nmol} / \mathrm{L}$, as compared to $18 \%$ among children in the same age group without an immigrant background. $7 \%$ of these children had high vitamin D levels above $75 \mathrm{nmol} / \mathrm{L}$, as compared to $13 \%$ in the comparison group (14).

\section{The influence of vitamin D on cancer and overall mortality}

The findings of geographical correlation studies (ecological studies) provided a major part of the motivation for the hypothesis that UV radiation affects the incidence of cancer (15). Many such studies, including some that were published only recently, suffer from basic methodological deficiencies that render it difficult to draw firm conclusions, despite the attempts that 
were made to control for certain confounding factors (e.g., urbanization, various measures of socioeconomic status, the rate of lung cancer as a surrogate for smoking behavior) (16). A finding that cancer incidence or mortality declines as one approaches the equator (i.e., as the amount of UV radiation increases) cannot suffice to establish an association between UV radiation, vitamin $\mathrm{D}$, and cancer.

The available observational studies regarding the potential association between vitamin $\mathrm{D}$ and cancer were subjected to multiple meta-analyses for the 2008 IARC report (6). Pooled analyses of the published risk estimators indicated an inverse relationship between 25-hydroxyvitamin D levels and carcinoma and adenoma of the bowel. For carcinoma of the bowel, a pooled analysis of nine case-control and cohort studies revealed a relative risk (RR) of 0.85 (95\% confidence interval [95\% CI], 0.79-0.91) for each $25 \mathrm{nmol} / \mathrm{L}$ rise in the serum vitamin D level. For adenoma (seven casecontrol and cohort studies), the relative risk was 0.93 (95\% CI, 0.88-0.99). For breast cancer, a pooled analysis of four case-control studies and one cohort study revealed a protective effect with a relative risk of 0.85 (95\% CI, 0.71-1.02) for each $25 \mathrm{nmol} / \mathrm{L}$ rise in the serum vitamin D level. For prostate cancer, however, no protective effect could be determined from the six case-control studies and one cohort study that were analyzed (RR 0.98; 95\% CI 0.92-1.05). Moreover, two interventional trials that were performed in the framework of the randomized, double-blind, placebocontrolled Women's Health Initiative (WHI) Study in the USA, which involved 36282 women aged 50 to 79 (e1, e2), as well as a British randomized, controlled trial (RCT) with 2686 participants aged 65 to 84 (e3), did not reveal any effect on the incidence of bowel or breast cancer through vitamin D supplementation (10 $\mu \mathrm{g}$ [400 IU]/day in the WHI trials, $41 \mu \mathrm{g}$ [1640 IU]/day in the British trial). Very recently, a clinical trial involving 1,179 women in Nebraska showed that the incidence of breast cancer was lowered by daily supplementation with $27.5 \mu \mathrm{g}$ (1100 IU) of vitamin $\mathrm{D}$, given in combination with calcium (e4). The main methodological problems of these clinical trials were uncertain compliance and lack of information about vitamin D levels before the intervention. Extensive further documentation of each of these studies can be found in the IARC report.

A meta-analysis of 18 RCTs led to the conclusion that vitamin $\mathrm{D}$ supplementation (12 to $15 \mu \mathrm{g} /$ day) lowers overall mortality (17). An analysis by the American National Health and Nutrition Examination Survey (NHANES III) revealed elevated mortality among persons with low vitamin D levels but did not identify any specific cause of death that could account for this finding (www.cdc.gov/nchs/nhanes/ nhanes_questionnaires.htm). The Cochrane is currently initiating systematic reviews on vitamin $\mathrm{D}$, cancer prevention, and mortality (e5, e6).

A recent multinational prospective study on the potential link between vitamin $\mathrm{D}$ serum levels and cancers of seven different, less common types (cancer of the endometrium, ovary, esophagus, stomach, kidney, and pancreas, and non-Hodgkin's lymphoma) did not reveal an association with any of these types of cancer (18).

\section{What level of vitamin $D$ is best?}

This question probably has a different answer depending on the particular health effect that is sought. A review published in 2006 (19) addressed the question of the optimal serum levels of vitamin D with regard to bone density, lower extremity function, dental health, and the risk of falling. Although the medical societies in many countries consider values of $50 \mathrm{nmol} / \mathrm{L}$ or above to be adequate, some current publications quote optimal levels above $75 \mathrm{nmol} / \mathrm{L}$ (e7, e8). The proponents of high vitamin $\mathrm{D}$ levels point out that protective effects against cancer are presumed to be achievable mainly with relatively high vitamin D levels (i.e., levels of $75 \mathrm{nmol} / \mathrm{L}$ or above) (e9). The therapeutic window for vitamin $\mathrm{D}$ is very wide: a toxic effect (hypercalcemia) is thought to arise only when the serum level exceeds $500 \mathrm{nmol} / \mathrm{L}$ (20). The European Union has set a blood level of $200 \mathrm{nmol} / \mathrm{L}$, corresponding to a daily intake of $100 \mu \mathrm{g}$ (4000 IU) of vitamin D, as the upper limit of the range in which no deleterious effects are observed. If one incorporates an additional safety margin, one arrives at a recommendation to take no more than $50 \mu \mathrm{g}$ (2000 IU) of vitamin D by mouth each day (e10). When the UV index is 6 , as on a summer's day in Germany, a light-skinned person with skin type II has to spend about 16 minutes in the sun (with $6 \%$ of the skin surface exposed) to synthesize $400 \mathrm{IU}$ of vitamin D (Table 1).

\section{Recommendations from various countries}

Recommendations on the daily intake of vitamin D have been issued in many countries. Most are riskadapted, i.e., higher daily doses are generally recommended for pregnant women, nursing mothers, infants, and the elderly than for children, adolescents, and young and middle-aged adults (Table 2). The Canadian Paediatric Society recommends a daily intake of at least $5 \mu \mathrm{g}(200 \mathrm{IU})$ and at most $50 \mu \mathrm{g}$ (2000 IU) of vitamin D for pregnant women and nursing mothers. In the German-speaking countries, the medical societies recommend daily doses varying from 5 to $10 \mu \mathrm{g}$, depending on the risk group. The German S3 guideline on the prevention, diagnosis, and treatment of osteoporosis in adulthood contains information on vitamin D intake (see www.dv-osteologie.de) (Table 2).

According to the IARC report (6), the following two questions will need to be answered before it can be determined what vitamin D level is best for the health of any particular individual (with a large degree of variation expected from one person to another):

- Does a low vitamin D level increase the risk of cancer?

- Does a low vitamin D level itself reflect poor health (i.e., could it be an effect, rather than a cause)? 
Current recommendations for daily vitamin $D$ intake in different countries

\begin{tabular}{|c|c|c|c|c|c|c|c|c|}
\hline \multirow[t]{2}{*}{ Country / institution } & \multicolumn{5}{|c|}{ Age (years) } & \multirow{2}{*}{$\begin{array}{l}\text { Pregnant } \\
\text { women }\end{array}$} & \multirow{2}{*}{$\begin{array}{l}\text { Nursing } \\
\text { mothers }\end{array}$} & \multirow{2}{*}{$\begin{array}{l}\text { Date of recom } \\
\text { mendation }\end{array}$} \\
\hline & $0-13$ & $14-18$ & $19-50$ & $51-70$ & $71+$ & & & \\
\hline $\begin{array}{l}\text { USA (e20-22): } \\
\text { - Food \& Nutrition Board (FNB)/Institute of Medicine }{ }^{\star^{1}} \\
\text { - American Academy of Pediatrics (AAP) }{ }^{2^{2}} \\
\text { - National Osteoporosis Foundation }\end{array}$ & $\begin{array}{l}5 \mu \mathrm{g} \\
10 \mu \mathrm{g} \\
10 \mu \mathrm{g}\end{array}$ & $\begin{array}{l}5 \mu \mathrm{g} \\
10 \mu \mathrm{g} \\
10 \mu \mathrm{g}\end{array}$ & $\begin{array}{l}5 \mu \mathrm{g} \\
- \\
10-20 \mu \mathrm{g}\end{array}$ & $\begin{array}{l}10 \mu g \\
- \\
20-25 \mu g\end{array}$ & $\begin{array}{l}15 \mu g \\
- \\
20-25 \mu g\end{array}$ & $\begin{array}{l}5 \mu \mathrm{g} \\
- \\
-\end{array}$ & $\begin{array}{l}5 \mu \mathrm{g} \\
- \\
-\end{array}$ & $\begin{array}{l}1997 \\
\text { August } 2008 \\
\text { July } 2007\end{array}$ \\
\hline $\begin{array}{l}\text { Reference values jointly issued by the German, } \\
\text { Austrian, and Swiss societies for nutrition (e23): } \\
\text { - German Society for Nutrition, DGE } \\
\text { - Austrian Society for Nutrition, ÖGE } \\
\text { - Swiss Society for Nutrition Research, SGE } \\
\text { - Swiss Association for Nutrition, SVE }\end{array}$ & $10 \mu g$ & $5 \mu \mathrm{g}$ & $5 \mu g$ & $5 \mu g^{\star^{3}}$ & $10 \mu g^{*^{3}}$ & $5 \mu g$ & $5 \mu \mathrm{g}$ & 2000 \\
\hline $\begin{array}{l}\text { Canada (e24-25): } \\
\text { - Health Canada * } \\
\text { - Canadian Cancer Society } *^{5} \\
\text { - Canadian Paediatric Society }{ }^{* 6}\end{array}$ & $\begin{array}{l}5-10 \mu \mathrm{g} \\
- \\
10 \mu \mathrm{g}\end{array}$ & $\begin{array}{l}5 \mu \mathrm{g} \\
- \\
10 \mu \mathrm{g}\end{array}$ & $\begin{array}{l}5 \mu \mathrm{g} \\
25 \mu \mathrm{g} \\
-\end{array}$ & $\begin{array}{l}10 \mu \mathrm{g} \\
25 \mu \mathrm{g} \\
-\end{array}$ & $\begin{array}{l}15 \mu \mathrm{g} \\
25 \mu \mathrm{g} \\
-\end{array}$ & $\begin{array}{l}5 \mu \mathrm{g} \\
- \\
50 \mu \mathrm{g}\end{array}$ & $\begin{array}{l}5 \mu \mathrm{g} \\
- \\
50 \mu \mathrm{g}\end{array}$ & $\begin{array}{l}\text { IOM } 1997 \\
\text { June } 2007 \\
2007\end{array}$ \\
\hline $\begin{array}{l}\text { Australia and New Zealand (e26): } \\
\text { - National Health and Medical Research Council }\end{array}$ & $5 \mu \mathrm{g}$ & $5 \mu \mathrm{g}$ & $5 \mu \mathrm{g}$ & $10 \mathrm{~g}$ & $15 \mathrm{~g}$ & $5 \mu g$ & $5 \mu g$ & 2006 \\
\hline $\begin{array}{l}\text { Ireland (e27): } \\
\text { - Food and Safety Authority *7}\end{array}$ & $5 \mu g$ & - & - & - & - & - & - & 2007 \\
\hline $\begin{array}{l}\text { United Kingdom } \star^{8}(\mathrm{e} 28) \text { : } \\
\text { - Health Department }\end{array}$ & $10 \mu \mathrm{g}$ & - & - & - & - & $10 \mu g$ & $10 \mu \mathrm{g}$ & 2007 \\
\hline Nordic countries ${ }^{\star 9}(\mathrm{e} 29)$ : & $7.5 \mu \mathrm{g}$ & $7.5 \mu \mathrm{g}$ & $7.5 \mu \mathrm{g}$ & $7.5 \mu \mathrm{g}$ & $10 \mu \mathrm{g}$ & - & - & 2004 \\
\hline $\begin{array}{l}\text { The Netherlands }(\mathrm{e} 30) \text { : } \\
\text { - Health Council } * 10\end{array}$ & $10 \mu \mathrm{g}$ & $10 \mu \mathrm{g}$ & $10 \mu \mathrm{g}$ & $10 / 20 \mu \mathrm{g}$ & $10 / 20 \mu \mathrm{g}$ & $10 \mu \mathrm{g}$ & $10 \mu \mathrm{g}$ & 2008 \\
\hline
\end{tabular}

DGE, Deutsche Gesellschaft für Ernährung ÖGE, Österreichische Gesellschaft für Ernährung SGE,Schweizerische Gesellschaft für Ernährungsforschung SVE:Schweizerische Vereinigung für Ernährung $1 \mu \mathrm{g}$ (microgram) = $40 \mathrm{IU}$ (International Units)

${ }^{* 1}$ The Institute of Medicine (IOM) will soon be issuing updated recommendations. ${ }^{{ }^{* 2}}$ This recommendation applies to children and adolescents who consume less than $1000 \mathrm{~mL}$ of infant formula (with basic vitamin supplementation) or milk per day.

${ }^{* 3} 10 \mu \mathrm{g}$ are recommended for infants aged 7 days to 1 year, then $5 \mu \mathrm{g}$ up to age 65 and $10 \mu \mathrm{g}$ thereafter.

${ }^{* 4}$ The recommendations for infants ( $0-12$ months) has been $10 \mu g$ since 2004.

${ }^{* 5} 25 \mu \mathrm{g}$ are recommended for adults in the fall and winter months. The elderly, persons with dark skin, those who rarely go outdoors, and those who habitually wear clothes that cover practically the entire body should consume $25 \mu \mathrm{g}$ all year round. ${ }^{*}$ Infants and small children living in northern Canada should consume $20 \mu \mathrm{g}$ of vitamin $\mathrm{D}$ in the winter months (October through April). *7 This recommendation applies to infants aged 0-12 months. Recommendations for older children and adults have not yet been issued. ${ }^{* 8}$ Pregnant women, nursing mothers, and children under age 4 should take vitamin D supplements in the winter months. The general public is advised to consume food that is rich in vitamin D, such as fish, and to spend 15-30 minutes outside in the sun every day during the summer months. Persons with darker skin are advised to spend longer times in the sun. ${ }^{* 9} 7.5 \mu \mathrm{g}$ are recommended for persons aged 2 to 60 , and $10 \mu \mathrm{g}$ for persons over 60 .

${ }^{* 10}$ The recommendation of $10 \mu \mathrm{g}$ applies to the following groups of people: Children under age 4 who consume less than $500 \mathrm{~mL}$ of infant formula or enriched milk daily; women under age 50 (men under age 70) who have dark skin and/or rarely go outdoors; veiled women under age 50; light-skinned women aged 50 or older (men aged 70 or older). The recommendation of $20 \mu \mathrm{g}$ applies to persons with osteoporosis, women aged 50 or older (men aged 70 or older) who have dark skin and/or rarely go outdoors, and veiled women aged 50 or older

The IARC favors the performance of further randomized trials, including trials of oral vitamin D supplementation, to answer these questions of causation. Although such trials are the only way to obtain therapeutically useful information on the possible influence of vitamin D on cancer incidence and mortality, they would probably yield results only after many years. Furthermore, difficulties may be anticipated with issues such as compliance and the quantification of individual UV exposure over time, given the period of the study.

\section{The prevention of skin cancer}

Solar UVA and UVB rays reach the earth's surface. UVB has a much stronger biological effect than UVA with respect to the induction of erythema and the generation of damage to DNA, but UVB is also responsible for the induction of vitamin $\mathrm{D}$ synthesis. The spectra of activity for vitamin D production and for DNA damage overlap to a large extent (eBox 2).

In view of the high prevalence of skin cancer, primary prevention campaigns against high UV exposure have been carried out in many countries. Their main goal is to lower the morbidity and mortality due to skin cancer (21). In Germany, for example, a campaign of this type has long been a component of the Life Phases Program (Lebensphasenprogramm) (22) of the Task Force on Dermatological Prevention (Arbeitsgemeinschaft Dermatologische Prävention, ADP) and the German Cancer Aid Society (Deutsche Krebshilfe, DKH): Persons at different stages of life, mainly adolescents, 
are given specific information about the health risks of UV radiation. Skin cancer screening was introduced in Germany in July 2008 with the goal of improving the early detection (i.e., secondary prevention) of skin cancer in older persons (aged 35 and above). In Germany and around the world, programs of this type are being carried out in view of the clear demonstration, by a large number of scientific studies, that UV radiation (UVA and UVB, either singly or in combination) acts as a carcinogen in and of itself and is causally linked to the induction, promotion, and progression of skin cancer (e11-e16). With respect to malignant melanoma, it has been found that sunburns and intermittent UV exposures increase the risk of melanoma, but a low level of chronic exposure to the sun does not. On the other hand, non-melanocytic types of skin cancer are associated with the cumulative lifetime exposure to UV light (23). In a recent re-evaluation of the available data, the IARC has listed both solar UV radiation and artificial UV radiation (from solaria) as group 1 carcinogens (24).

\section{Summary}

Although there is already evidence for a protective effect of vitamin D against some types of cancer, much research still needs to be done. The high, and increasing, incidence of skin cancer among older and younger persons alike implies that comprehensive UV protection will remain indispensable in the future. The medical societies' recommendations in Germany and elsewhere emphasize the importance of avoiding sunburn, and exposure to the sun, at times when the UV intensity is highest, i.e., around midday. In the summer months, short UV exposures of up to 15 minutes per day on parts of the body not covered by clothing, such as the face, hands, and arms, are considered to suffice for adequate vitamin D synthesis and are recommended, in particular, to persons in certain risk groups in order to ensure that physiological amounts of vitamin D are produced. The risk of skin cancer arising from such brief exposure to the sun seems negligible compared to its benefits. One must recall, however, that solar UV light may not be intense enough to ensure adequate vitamin $\mathrm{D}$ synthesis in the fall and winter months, particularly at higher latitudes. There are, theoretically, three further options for the elevation of low vitamin $\mathrm{D}$ levels among the population subgroups at risk:

- artificial UV exposure in solaria and the like;

- increased dietary intake of vitamin D as part of the ordinary diet;

- vitamin D supplementation and medical treatment of persons with low vitamin D levels.

Exposure to artificial UV rays in solaria is, like solar UV exposure, a proven risk factor for skin cancer. The UV intensity in solaria commonly reaches, or exceeds, that of the midday sun at the equator, and there is thus a risk that the minimal erythema dose will also be exceeded, with resulting damage to health (25). Furthermore, typical solarium users do not belong to any of the risk groups for vitamin D deficiency (e.g., children, the elderly, immigrants); they also generally have light skin and thus belong precisely to the group of people in whom UV exposure most increases the risk of skin cancer. Thus, solaria and prolonged exposures (more than 15 minutes daily) seem to carry excessive risk compared to solar UV and are, therefore, not recommended as a means of raising vitamin D levels.

The dietary intake of vitamin D is coupled to particular foods; thus, it can probably be raised only in exceptional cases, e.g., by the regular consumption of fish oil. Among old women in Japan, regular fish consumption (4 or more times per week) is associated with high levels of vitamin D (e17). In view of the price and less than universal availability of fish as food, elevating fish consumption would not seem to be a practical strategy for broadly improving vitamin D status across the world.

A moderate increase in individual exposure to sunlight, with observance of the basic guidelines for protection against excessive UV exposure, should be considered as a basic measure for use in clinical practice. This can be achieved, for example, by more outdoor exercise. Vitamin D supplementation can be given in addition, or as an alternative, and might also have further beneficial effects on health, e.g., antihypertensive effects, as the current literature suggests (e18). In particular, oral vitamin D supplementation is an indicated treatment for persons with clinically relevant vitamin D deficiency. In the light of current views about optimal vitamin D levels, it would seem appropriate to give higher doses of vitamin $\mathrm{D}$ to some patients, depending on their individual vitamin $\mathrm{D}$ status, their membership in a risk group, and/or the time of year. We are convinced that the twin goals of preventing skin cancer and improving vitamin $\mathrm{D}$ status can be met by preventive intervention, and that neither goal must be sacrificed to achieve the other.

\section{Conflict of Interest Statement \\ The authors declare that they have no conflict of interest as defined by the guidelines of the International Committee of Medical Journal Editors.}

Manuscript submitted on 4 May 2009; revised version accepted on 17 November 2009.

Translated from the original German by Ethan Taub, M.D.

\section{REFERENCES}

1. Webb AR, Pilbeam C, Hanafin N, Holick MF: An evaluation of the relative contributions of exposure to sunlight and of diet to the circulating concentrations of 25-hydroxyvitamin D in an elderly nursing home population in Boston. Am J Clin Nutr 1990; 51: 1075-81.

2. Holick MF, Chen TC: Vitamin D deficiency: a worldwide problem with health consequences. Am J Clin Nutr 2008; 87: 1080S-6S.

3. Davis CD: Vitamin D and cancer: current dilemmas and future research needs. Am J Clin Nutr 2008; 88: 565S-9S.

4. Wei MY, Garland CF, Gorham ED, Mohr SB, Giovannucci E: Vitamin $\mathrm{D}$ and prevention of colorectal adenoma: a meta-analysis. Cancer Epidemiol Biomarkers Prev 2008; 17: 2958-69.

5. Bertone-Johnson ER: Vitamin D and Breast Cancer. Ann Epidemiol 2009; 19: 462-7. 
6. IARC Working Group on Vitamin D: Vitamin D and Cancer. Lyon: IARC 2008

7. Katalinic A, Kunze U, Schafer T: Epidemiology of cutaneous melanoma and non-melanoma skin cancer in Schleswig-Holstein, Germany: incidence, clinical subtypes, tumour stages and localization (epidemiology of skin cancer). Br J Dermatol 2003; 149: 1200-6.

8. Hirani V, Primatesta P: Vitamin D concentrations among people aged 65 years and over living in private households and institutions in England: population survey. Age Ageing 2005; 34: 485-91.

9. Andersen R, Molgaard C, Skovgaard LT, et al.: Pakistani immigrant children and adults in Denmark have severely low vitamin D status. Eur J Clin Nutr 2008; 62: 625-34.

10. Holick MF: Vitamin D deficiency. N Engl J Med 2007; 357: 266-81.

11. Barger-Lux MJ, Heaney RP: Effects of above average summer sun exposure on serum 25-hydroxyvitamin D and calcium absorption. J Clin Endocrinol Metab 2002; 87: 4952-6.

12. Hintzpeter B, Mensink GB, Thierfelder W, Muller MJ, Scheidt-Nave $C$ : Vitamin D status and health correlates among German adults. Eur J Clin Nutr 2008; 62: 1079-89.

13. Abbas S, Linseisen J, Slanger T, et al.: Serum 25-hydroxyvitamin D and risk of post-menopausal breast cancer-results of a large case-control study. Carcinogenesis 2008; 29: 93-9.

14. Hintzpeter B, Scheidt-Nave C, Muller MJ, Schenk L, Mensink GB: Higher prevalence of vitamin $D$ deficiency is associated with immigrant background among children and adolescents in Germany. J Nutr 2008; 138: 1482-90.

15. Mohr SB: A brief history of vitamin D and cancer prevention. Ann Epidemiol 2009; 19: 79-83.

16. Grant WB, Garland CF: The association of solar ultraviolet $B$ (UVB) with reducing risk of cancer: multifactorial ecologic analysis of geographic variation in age-adjusted cancer mortality rates. Anticancer Res 2006; 26: 2687-99.

17. Autier P, Gandini S: Vitamin D supplementation and total mortality: a meta-analysis of randomized controlled trials. Arch Intern Med 2007; 167: 1730-7.
18. Helzlsouer KJ, VDPP Steering Committee: Overview of the cohort consortium vitamin D pooling project of rarer cancers. Am J Epidemiol 2010; 172: 4-9.

19. Bischoff-Ferrari HA, Giovannucci E, Willett WC, Dietrich T, DawsonHughes B: Estimation of optimal serum concentrations of 25hydroxyvitamin D for multiple health outcomes. Am J Clin Nutr 2006; 84: 18-28.

20. Jones G: Pharmacokinetics of vitamin D toxicity. Am J Clin Nutr 2008; 88: 582S-6S.

21. Greinert R, Breitbart EW, Mohar P, Volkmer B: Health initiatives for the prevention of skin cancer. Adv Exp Med Biol 2008; 624: 125-36.

22. Breitbart EW, Greinert R, Volkmer B: Effectiveness of information campaigns. Prog Biophys Mol Biol 2006; 92: 167-72.

23. Leiter $\mathrm{U}$, Garbe $\mathrm{C}$ : Epidemiology of melanoma and nonmelanoma skin cancer-the role of sunlight. Adv Exp Med Biol 2008; 624: 89-103.

24. El GF, Baan R, Straif K, et al.: A review of human carcinogens-part D: radiation. Lancet Oncol 2009; 10: 751-2.

25. Oliver H, Ferguson J, Moseley H: Quantitative risk assessment of sunbeds: impact of new high power lamps. Br J Dermatol 2007; 157: $350-6$

\section{Corresponding autho}

Prof. Dr. med. Hajo Zeeb

Bremer Institut für Präventionsforschung und Sozialmedizin (BIPS)

Universität Bremen

Linzer Straße 10

28359 Bremen, Germany

zeeb@bips.uni-bremen.de

For eReferences please refer to:

www.aerzteblatt-international.de/ref3710

eBoxes available at:

www.aerzteblatt-international.de/article10m0638 


\title{
The Role of Vitamin D in Cancer Prevention
}

\author{
Does UV Protection Conflict With the Need to Raise Low Levels of Vitamin D?
}

\author{
Hajo Zeeb, Rüdiger Greinert
}

\section{EREFERENCES}

e1. Wactawski-Wende J, Kotchen JM, Anderson GL, et al.: Calcium plus vitamin $\mathrm{D}$ supplementation and the risk of colorectal cancer N Engl J Med 2006; 354: 684-96.

e2. Chlebowski RT, Johnson KC, Kooperberg C, et al.: Calcium plus vitamin D supplementation and the risk of breast cancer. J Natl Cancer Inst 2008; 100: 1581-91.

e3. Trivedi DP, Doll R, Khaw KT: Effect of four monthly oral vitamin D3 (cholecalciferol) supplementation on fractures and mortality in men and women living in the community: randomised double blind controlled trial. BMJ 2003; 326: 469.

e4. Lappe JM, Travers-Gustafson D, Davies KM, Recker RR, Heaney RP: Vitamin D and calcium supplementation reduces cancer risk: results of a randomized trial. Am J Clin Nutr 2007; 85: 1586-91.

e5. Bjelakovic G, Gluud LL, Nikolova D, Whitfield K, Wetterslev J, Gluud C: Vitamin D supplementation for prevention of mortality in adults (Protocol). Cochrane Database of Systematic Reviews (4), CD007470. DOI: 10.1002/14651858.CD007470. 2008.

e6. Bjelakovic G, Gluud LL, Nikolova D, Whitfield K, Wetterslev J, Gluud C: Vitamin D supplementation for prevention of cancer in adults (Protocol). Cochrane Database of Systematic Reviews (4), CD007469. DOl: 10.1002/14651858.CD007469. 2008.

e7. Heaney RP: Vitamin D in health and disease. Clin J Am Soc Nephrol 2008; 3: 1535-41.

e8. Mosekilde L: Vitamin D requirement and setting recommendation levels: long-term perspectives. Nutr Rev 2008; 66: S170-7.

e9. Grant WB, Garland CF, Gorham ED: An estimate of cancer mortality rate reductions in Europe and the US with 1,000 IU of oral vitamin D per day. Recent Results Cancer Res 2007; 174: 225-34.

e10. EC Scientific Committee on Food: Opinion of the Scientific Committee on Food on the Tolerable Upper Intake Level of Vitamin D. 2002. Bruxelles: European Commission, Health and Consumer Protection Directorate-General. http://ec.europa.eu/food/fs/sc/ scf/out157_en.pdf, Abfrage 7.10.2008

e11. Matsumura Y, Ananthaswamy HN: Short-term and long-term cellular and molecular events following UV irradiation of skin: implications for molecular medicine. Expert Rev Mol Med 2002; 4: $1-22$.

e12. Melnikova VO, Ananthaswamy HN: Cellular and molecular events leading to the development of skin cancer. Mutat Res 2005; 571: 91-106.

e13. Gandini S, Sera F, Cattaruzza MS, et al.: Meta-analysis of risk factors for cutaneous melanoma: II. Sun exposure. Eur J Cancer 2005; 41: 45-60.

e14. Gandini S, Sera F, Cattaruzza MS, et al.: Meta-analysis of risk factors for cutaneous melanoma: III. Family history, actinic damage and phenotypic factors. Eur J Cancer 2005; 41: 2040-59.

e15. Gandini S, Sera F, Cattaruzza MS, et al.: Meta-analysis of risk factors for cutaneous melanoma: I. Common and atypical naevi. Eur J Cancer 2005; 41: 28-44. e16. Armstrong BK, Kricker A: The epidemiology of UV induced skin cancer. J Photochem Photobiol B 2001; 63: 8-18.

e17. Nakamura K, Nashimoto M, Hori Y, Yamamoto M: Serum 25-hydroxyvitamin $\mathrm{D}$ concentrations and related dietary factors in periand postmenopausal Japanese women. Am J Clin Nutr 2000; 71: $1161-5$.

e18. Pilz S, Tomaschitz A, Ritz E, Pieber TR: Vitamin D status and arterial hypertension: a systematic review. Nat Rev Cardiol 2009; 6: 621-30.

e19. Matsuoka LY, Ide L, Wortsman J, MacLaughlin JA, Holick MF: Sunscreens suppress cutaneous vitamin D3 synthesis. J Clin Endocrinol Metab 1987; 64: 1165-8.

e20. Food \& Nutrition Board (FNB)/Institute of Medicine: Dietary Supplement Fact Sheet: Vitamin D. http://ods.od. nih.gov/factsheets/vitamind.asp; Aufruf 07.10.2008

e21. American Academy of Paediatrics (AAP): New vitamin D recommendation for children. http://dr-razavi.blogspot.com/ 2008/08/new-vitamin-d-recommendation-for.html; Aufruf 07.10 .2008

e22. National Osteoporosis Foundation: www.nof.org/prevention/cal cium_and_VitaminD.htm; Aufruf 07.10.2008

e23. DACH: Referenzwerte für die Nährstoffzufuhr: www.acibas.net/ DACH-Werte/index.shtml; Aufruf 07.10.2008

e24. Health Canada http://www.hc-sc.gc.ca/fn-an/food-guide-aliment/ context/evid-fond/vita_d-eng.php; www.hc-sc.gc.ca/fn-an/nutri tion/child-enfant/infant-nourisson/vita_d_supp-eng.php; Aufruf 07.10.2008

e25. Canadian Paediatric Society: www.cps.ca/english/statements/ll/ FNIM07-01.htm.; Aufruf 07.10.2008

e26. National Health and Medical Research Council. Nutrient Reference Values for Australia and New Zealand Including Recommended Dietary Intakes. Canberra: Commonwealth of Australia and New Zealand Government, 2006.

e27. www.fsai.ie/publications/reports/vitaminD.pdf; Aufruf 07.10.2008

e28. www.healthystart.nhs.uk/en/fe/page. asp?n1=1\&n2=8\&n3=97\&n4=100; Aufruf 07.10.2008

e29. Becker (2005) Nordic Nutrition recommendations 2004, based on scientific evidence http://journals.sfu.ca/coaction/index.php/fnr/ article/viewFile/1524/1392; Aufruf 07.10.2008

e30. Health Council of the Netherlands. Towards an adequate intake of vitamin D. The Hague: Health Council of the Netherlands, 2008; publication no. 2008/15. Aufruf via

e31. www.gr.nl/referentie.php?|D=1756; Aufruf 30.1.2009

e32. Lamberg-Allardt C: Vitamin D in foods and as supplements. Prog Biophys Mol Biol 2006; 92: 33-8.

e33. Slaper H, Velders GJ, Daniel JS, de Gruijl FR, van der Leun JC: Estimates of ozone depletion and skin cancer incidence to examine the Vienna Convention achievements. Nature 1996; 384: 256-8. 
e34. Rosenstein BS, Mitchell DL: Action spectra for the induction of pyrimidine(6-4)pyrimidone photoproducts and cyclobutane pyrimidine dimers in normal human skin fibroblasts. Photochem Photobiol 1987; 45: 775-80.

e35. Matsumura Y, Ananthaswamy HN: Molecular mechanisms of photocarcinogenesis. Front Biosci 2002; 7: d765-83.

e36. Melnikova VO, Ananthaswamy HN: Cellular and molecular events leading to the development of skin cancer. Mutat Res 2005; 571: 91-106.

e37. Cleaver JE, Crowley E: UV damage, DNA repair and skin carcinogenesis. Front Biosci 2002; 7: d1024-43.

e38. Mouret S, Baudouin C, Charveron M, Favier A, Cadet J, Douki T: Cyclobutane pyrimidine dimers are predominant DNA lesions in whole human skin exposed to UVA radiation. Proc Natl Acad Sci USA 2006; 103: 13765-70.

e39. Tian XQ, Chen TC, Matsuoka LY, Wortsman J, Holick MF: Kinetic and thermodynamic studies of the conversion of previtamin D3 to vitamin D3 in human skin. J Biol Chem 1993; 268: 14888-92. e40. Adams JS, Clemens TL, Parrish JA, Holick MF: Vitamin-D synthesis and metabolism after ultraviolet irradiation of normal and vitamin-D-deficient subjects. N Engl J Med 1982; 306: 722-5.

e41. CIE: Action spectrum for the production of previtamin D3 in human Skin.Technical report 2006; 174, 1-12.

e42. Wolpowitz D, Gilchrest BA: The vitamin D questions: how much do you need and how should you get it? J Am Acad Dermatol 2006; 54: 301-17.

e43. de Gruijl FR: Skin cancer and solar UV radiation. Eur J Cancer 1999; 35: 2003-9.

e44. Holick MF: The cutaneous photosynthesis of previtamin D3: a unique photoendocrine system. J Invest Dermatol 1981; 77: 51-8.

e45. MacLaughlin JA, Anderson RR, Holick MF: Spectral character of sunlight modulates photosynthesis of previtamin D3 and its photoisomers in human skin. Science 1982; 216: 1001-3.

e46. Webb AR, DeCosta BR, Holick MF: Sunlight regulates the cutaneous production of vitamin D3 by causing its photodegradation. J Clin Endocrinol Metab 1989; 68: 882-7. 


\section{The Role of Vitamin D in Cancer Prevention}

Does UV Protection Conflict With the Need to Raise Low Levels of Vitamin D?

Hajo Zeeb, Rüdiger Greinert

eBOX 1

Vitamin D: physiology and sources

The concentration of 25-hydroxyvitamin D (25[OH]D) serves as a biomarker for vitamin $D$ status, which is very important for the maintenance of health and the functioning of many systems of the body. The precursor substance 7-dehydrocholesterol is photoisomerized by exposure to UVB, so that cholecalciferol (vitamin D3) is produced. Vitamin D3 is metabolized in the liver to $25(\mathrm{OH}) \mathrm{D}$ and can be stored as an intermediate metabolite or released into the bloodstream. The biologically active form, $1.25(\mathrm{OH})_{2} \mathrm{D}$, is generated mainly in the kidneys as the result of feedback from calcium or phosphate metabolism. Many target organs, including the kidneys, intestines, and bones, bear receptors for the active form of vitamin $D$.

Most of the circulating 25-hydroxyvitamin D is formed through UVB exposure. Most foods contribute little to the vitamin D level (31), although the total contribution from food varies widely depending on individual dietary habits and the time of year. Fish, particularly species that contain much fat, is the richest dietary source of vitamin D; meat, eggs, and dairy products contain much lower amounts. In some countries, vitamin D is added as a supplement to margarine, cereals, and other foods. Vitamin D tablets in various doses are available. In Germany, vitamin $D$ tablets can be obtained in doses ranging from $5 \mu \mathrm{g}(=200 \mathrm{IU})$ to $25 \mu \mathrm{g}(=1000 \mathrm{IU})$, also in combination with calcium carbonate. Other forms of administration (high-dose capsules, oils, intramuscular depot preparations) are available as well. 


\section{Ultraviolet radiation: DNA damage and vitamin D production}

The ultraviolet (UV) range of the electromagnetic spectrum of sunlight is divided into three wavelength ranges:

- UVC: 100 to $<280 \mathrm{~nm}$,

UVB: 280 to $<315 \mathrm{~nm}$, and

- UVA: 315 to $<400 \mathrm{~nm}$.

Only UVA and UVB rays reach the earth's surface, where UVA rays account for about $95 \%$ of the total UV exposure (e32). UVB rays, however, generally exert biological effects on the order of 1000 times stronger than UVA rays, because of their shorter wavelength. This is true both for the induction of skin erythema and for the induction of damage to DNA, e.g., cyclobutane-pyrimidine dimer (CPD) formation (e33). This classic type of pre-mutagenic DNA damage can, in turn, induce genomic mutations of characteristic types, so-called UV signature mutations (CC-TT or C-T) (e34). There is a well-documented causal link between these types of DNA damage and skin cancer (e35, e36). Moreover, it has recently been discovered that UVA radiation, too, can induce CPD formation in human skin in vivo (e37). In view of the high percentage of the solar spectrum that is made up of UVA rays, this finding highlights the mutagenic and carcinogenic effects of UV radiation.

UVB radiation induces the photosynthesis of vitamin D in the skin. Provitamin D3 (7-dehydrocholesterol, 7-DHC) is photochemically transformed into previtamin D3 through the absorption of UVB radiation. This reaction occurs in a few seconds; in contrast, the thermically induced isomerization of previtamin D3 to vitamin D in the skin has been reported to occur with a halflife of ca. 2.5 hours (e38). The maximal concentration of vitamin D3 in the blood is reached 12 to 24 hours after UVB exposure (e38, e39). An important fact is that the activity spectrum for previtamin D3 production ranges from 260 to $315 \mathrm{~nm}$ (e40), with maximum efficacy between 297 and $303 \mathrm{~nm}$. Thus, the activity spectrum for vitamin D production largely overlaps with the activity spectrum for the UV-dependent induction of premutagenic CPD, which are held to cause skin cancer, as well as with the activity spectrum for the induction of squamous-cell carcinoma of the skin in man (e41, e19, e42). Thus, vitamin D is produced through the influence of UV rays in parallel with UV-induced damage to DNA.

Excessive UV exposure increases the risk of skin cancer but does not cause a continuing increase in vitamin D concentration, because, in exposed skin, previtamin D3 is converted into the inactive isomers lumisterol and tachysterol within 5-10 minutes of UVB exposure. These isomers are in a quasi-stationary equilibrium with previtamin D3. Only when the concentration of previtamin D3 goes down again does renewed UVB exposure induce neosynthesis of vitamin D3 and stimulate reverse isomerization of lumisterol and tachysterol to previtamin D3. Thus, no more than $10 \%$ to $15 \%$ of the 7 -DHC concentration is ever converted into bioavailable vitamin D3 (e43, e44). Furthermore, vitamin D3 is very sensitive to the UVA component of the solar spectrum once it has been formed in the skin thorugh the thermally induced isomerization of previtamin D3. Further UV exposure leads to rapid photodegradation into a series of photoproducts such as 5.6-transvitamin D and suprasteol I and II. An experimental study in Boston revealed that $30 \%$ of cutaneous vitamin D was destroyed after 10 minutes of exposure to the sun on a summer day; after 30 and 60 minutes, this figure rose to $50 \%$ and $75 \%$ (e45). This explains why the vitamin $D$ levels of persons who are chronically exposed to the sun are in the high normal range, rather than being extremely elevated (11). Table 1 indicates the UV exposure times that are needed to produce defined amounts of vitamin D when only $6 \%$ of the total body surface (the hands and face) are exposed to various different levels of UV radiation. Dark-skinned persons need longer exposure times, on average, to reach a comparable serum level of vitamin $D$. 